\title{
CAPSTONE DESIGN PROJECTS: THEORY MEETS PRACTICE
}

\author{
Raghu Echempati ${ }^{*}$ and Several Senior Undergraduate Capstone Course \\ Students \\ ${ }^{1}$ College of Engineering, Kettering University, Flint, Michigan USA \\ Email: rechempa@kettering.edu
}

\begin{abstract}
This paper describes one example of an adjustable gooseneck trailer hitch assembly that was assigned as a senior capstone design project course at Kettering University, Flint, Michigan, USA to carry out their work from concept to testing phases of a real prototype - in short, following "Theory meets practice" concept. Typically at most other engineering colleges, students complete their capstone projects in one year, while at Kettering University, the students complete their capstone courses in one academic term that lasts only about 11 weeks. Using math and advanced Computer Aided Engineering (CAE) tools for analysis is expected. Three different groups of students enrolled in three separate courses over 3 academic terms developed two different trailer hitch devices. The first gooseneck hitch system briefly described here was the effort of a group of four students of the capstone course. They designed a manually adjustable device. However, due to time constraints, their fabricated device ended up being a rigid frame. These students carried out all the different tasks of the project more or less equitably. The second trailer hitch system described in this paper was the effort of a single student of the capstone course who designed and fabricated a compliant (adjustable) hitch system. However, due to time constraints, detailed finite element analysis (FEA) or testing of the device could not be done. A third group of two students enrolled in Applied Finite Element Analysis course in another academic term chose the compliant hitch design carried by the single student for their final class project, and attempted analysis by MatLab and FEA. Preliminary results obtained for both of these gooseneck trailer hitch systems are presented and discussed briefly in the paper. Majority of the capstone course projects carried out at Kettering University represent uniqueness in terms of completing them in one academic term.
\end{abstract}

Keywords: Capstone courses, gooseneck trailer hitch, Innovative \& low-cost mechanical design \& production, Assessment \& design communication, Finite element analysis, Ethics \& societal issues

https://doi.org/10.47412/LHDX6058

\section{Introduction}

It is well-known that capstone courses provide excellent opportunity to show-case students' final program outcomes and learning experiences of an academic department, college, and the university as a whole. They provide ultimate academic experience to students at the end of their academic career. Capstone courses build up on the learning outcomes from majority of the courses they take at undergraduate level and challenges them to innovatively select a project idea (sometimes called 'opportunities recognition'), brainstorm (sometimes called pain-storming) to choose candidate ideas for their feasibility of design, analysis, fabrication, assembly and testing phases. Often times, non-functional 3D printing parts are used for fabrication of some of the less load-bearing members of their fabricated devices. 
According to Tomorrow's Professor Postings on Teaching and Learning (Stanford University) [1], "Introducing [undergraduate] students to content that could make a contribution to their field has potential benefits to the students, faculty, institution, and discipline. From the student perspective, completing a research project with even the potential for publication provides a competitive advantage in gaining admission to graduate school or demonstrating discipline-related skills for the job market."

There are numerous papers available in the literature and published in American Society of Engineering Education (ASEE) and other technical and educational conference proceedings, posters, and journals. Funding agencies such as National Science Foundation (NSF) also encourage inter-collegiate capstone projects and classes coordinated both from within USA and between US colleges and colleges abroad. Now-a-days, many capstone classes in engineering and in business departments are undertaken keeping in view the needs of the communities and the societies we live in, and not necessarily only targeting the growth of engineering products for companies.

There are several views expressed by researchers on what capstone classes should be. Moore [2] views that a capstone course gives an opportunity to the students to demonstrate that they have achieved the goals for learning as established by their academic departments and the educational institution as a whole. Davis et al [3] produced a set of ten holistic roles of an engineer. These are categorized under three main roles such as technical role, interpersonal skills role, and professional role. Similar ideas are also expressed in Learning Professor [1], namely, “...capstone projects that are real to students help address the major student impediment we have noted: motivation. This is one of the premises of problem-based learning, industry internships and lab practicums as well. When students believe in the importance and legitimacy of the task, their psychic investment is higher and their motivation improves. Finally, a discipline can benefit by accumulating greater knowledge through student participation."

Plumley, et al [4] discussed the learning outcomes of assigning a common capstone project involving freshmen and senior students in the mechanical engineering department. In a recent paper, Lutz, et al [5] pointed out that real capstone courses should mimic authentic open-ended, real world engineering experiences involving an interaction with real clients and industry professionals. While this is very desirable and may be true to some colleges (for example, Harvey Mudd College, Claremont, California, etc.), it is not easy for others. The work in these projects may be to design and develop a new engineering system and test it on campus, or to carry out extensive experimental work at the industrial facility, which adds value to the quality of work carried. However, coordinating this with student groups will be very challenging due to their class schedules and also the safety issues.

On a different category, there are many papers available in the literature on undergraduate senior capstone design courses that are multi-disciplinary in nature in which, students from the same discipline (example, mechanical) working on a project that involves both mechanical, electrical, computer science and even business disciplines. Other projects involve group of students from other engineering, science and business departments working on the same project. Finally, students carry projects that involve group of students from other colleges both from within USA and/or global. Some of these are community-oriented projects. Managing multi-team and global capstone projects require lot of planning between the instructors and also need support from the respective college administrations.

Regardless of how diverse the ideas are about capstone classes, the main objectives of a capstone course is to follow a systematic design process which includes: recognition of opportunities that help in generating several ideas for the project, brainstorming conceptual ideas that result in developing preliminary designs, performing iterative designs using CAE and math tools to achieve optimum design, carry out analysis on the optimized design, procuring material, fabrication of the prototype, testing the device based on the original objectives, and finally, discussing (assessing) the strengths and weaknesses of their project work. The above process by no means is a serial activity, but it is iterative by revisiting the main stages of the design, manufacturing and testing cycles several times to assure that their designs shape up to reality. 
Students are also expected to discuss the scalability of the project idea to other potential applications. Finally, they are expected to document the difficulties and hurdles if any, faced during any stages of their product and process cycles, and what steps and changes are needed to be done at which design process stage, to overcome the difficulties faced.

Based on the several capstone projects carried out by the senior students at Kettering University [6], the present author discussed the challenges faced by the students, the learning outcomes, and the different assessment tools used to judge the quality of their work at two different conferences [7, 8]. The main aim of the present paper is to provide brief technical details of one example project that were not published earlier in any conference. Assessment of these and other projects will be presented in another forthcoming conference. In the next few sections, brief details about two different designs of the same capstone project are presented along with their performance metrics, namely, whether the original objectives of the project ideas are achieved, and if not, whether the students identified the short-comings of their designs and proposed solution to address these. Each project report contains several items to be covered including the safety issues, ethics and impact to society due to poor designs. There are many other metrics used to grade these projects.

The title of the current capstone course is Mechanical Systems Design Project. This course is offered during Summer and Fall terms each year. There are 4 other capstone courses offered during these and other terms. These different capstone courses and the projects within them are based on the specialties we have within the mechanical engineering department. Students need to take only one capstone course of their choice that fits their interest and class schedules. In each capstone course, there are usually 10 to 20 students. The number of students within a group is usually 3 to 5 depending amount of work perceived to be involved in each design project. This can change if a student withdraws from the course. We provide funds up to US $\$ 300$ per group to cover the costs of the fabricated device. This amount is usually sufficient since the students can use the stock or recycled material available in the department. Brief details of one of the capstone projects is presented in the next section.

\section{Capstone Design Project - Theory Meets Practice}

\subsection{Low-cost adjustable goose-neck automotive hitch assembly [6]}

\subsubsection{Background and need}

The gooseneck ball trailer hitch design has been around for more than 50 years with virtually no updates during that time. The name 'gooseneck' is used as it resembles the neck of a goose as shown in Fig. 1 (a) and (b). Figure 1 (a) is the digital image of a gooseneck trailer attached to a tandem axle pickup truck, while Fig. 1(b) shows the photograph of a real trailer attached to a heavy-duty pickup truck.
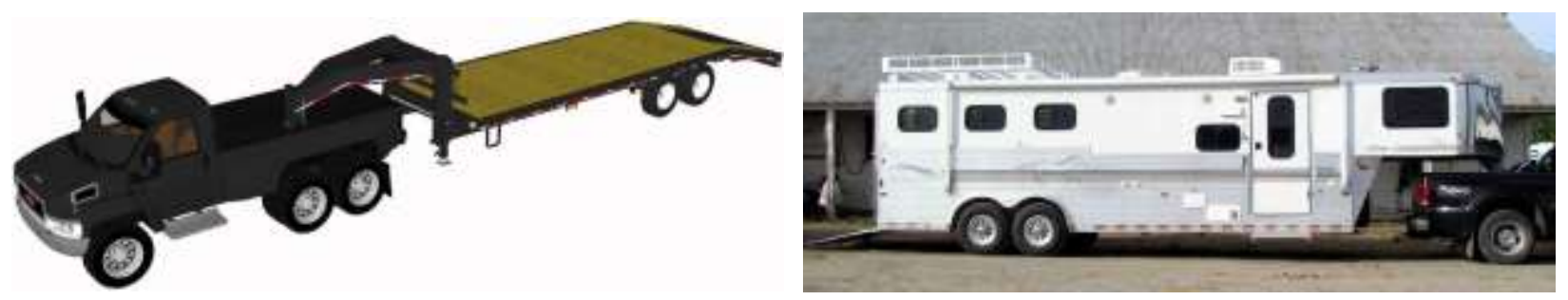

Figure 1: Examples of conventional gooseneck trailers attached to a pickup truck [en.wikipedia.org].

One of the main advantages of a gooseneck trailer shown in Fig. 2(a) over a rear bumper pull (or $5^{\text {th }}$ wheel hitch) shown in Fig. 2(b), is its stability and its load carrying (tow) capacity, which can be up to 30,000 
pounds. Since the tongue weight of the trailer is over the truck's rear axle instead of at the back of the chassis frame, the potential of the trailer to sway is minimized. With the increasing demand for driver and towing comfort, both large and small trucks are tasked with acting more like typical passenger cars when the element of ride quality is discussed. As these trucks receive more compliant suspensions from their manufacturers, one thing that should follow would be a more flexible hitch setup that will offer the driver and passengers more comfort while towing. The aim of the new design proposed in this work is to incorporate a swing arm setup with bushings on the arm to reduce the jarring that is inherent in towing over rough roads, or the shifting of the load that occurs when transporting non-secure loads. This case is typical when towing liquids or livestock. The proposed design is not intended to increase the load carrying capacity, it is meant to reduce the jarring.

\subsubsection{Market research and current designs}

As mentioned above, currently, there are many hitch designs available in the market, but they are not soft or flexible. Example of a standard hitch system is shown in Fig. 2(a). This is welded or mounted on a rail in the truck bed. The airbag hitch assembly shown in Fig. 3 is flexible in the vertical direction only and not in the direction of towing. Similarly, there are many other devices for use with different vehicles from different years. Cost of a typical gooseneck trailer hitch can be between US $\$ 500$ to US $\$ 1,000$.
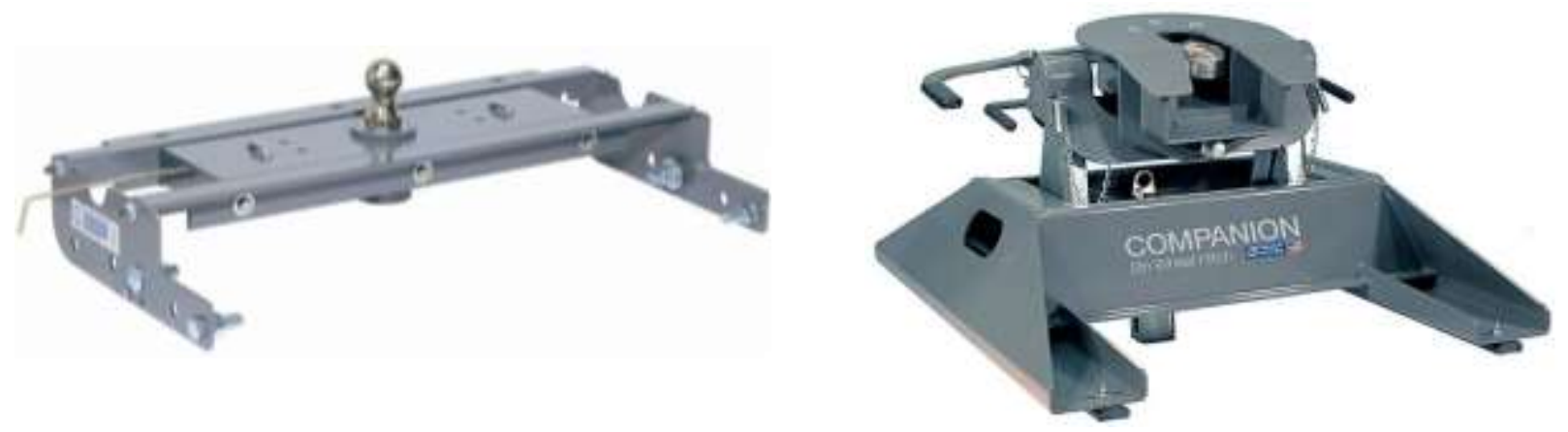

Figure 2: Typical hitch assemblies (a) gooseneck, and (b) $5^{\text {th }}$ wheel [sdtrucksprings.com].

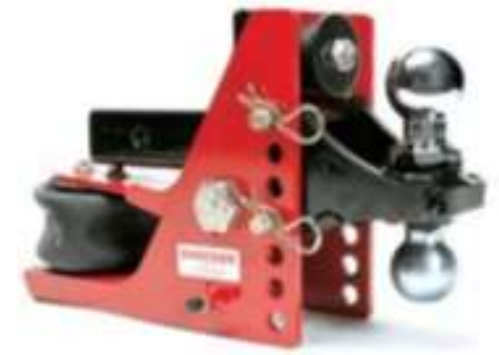

Figure 3: Example of an airbag hitch assembly [realtruck.com].

Trailer hitch systems need to be carefully designed to avoid or to minimize the potential accidents due to traffic and driving conditions. These cause safety concerns and impact on otherwise smooth traffic flow conditions due to jamming that cause delays. The image of the company manufacturing such devices, and its employees can face product recalls and reduced profit margins. 


\subsubsection{First trailer hitch design}

The first group of students developed a trailer hitch design during Fall 2017 academic term. In all, there were 20 students in the class. There were 5 groups with 4 students each in each group. So there were 5 different projects chosen during this term. The manually adjustable gooseneck trailer system shown in Fig. 4 of this paper was one of the projects carried by 4 students during this term. This design ended up being a rigid frame in contrast to their originally planned manually adjustable device. This is shown in Fig. 4 . The complete details of this design, analysis and assessment have been published in another earlier conferences $[7,8]$. Therefore, the details of the design calculations are not presented here.
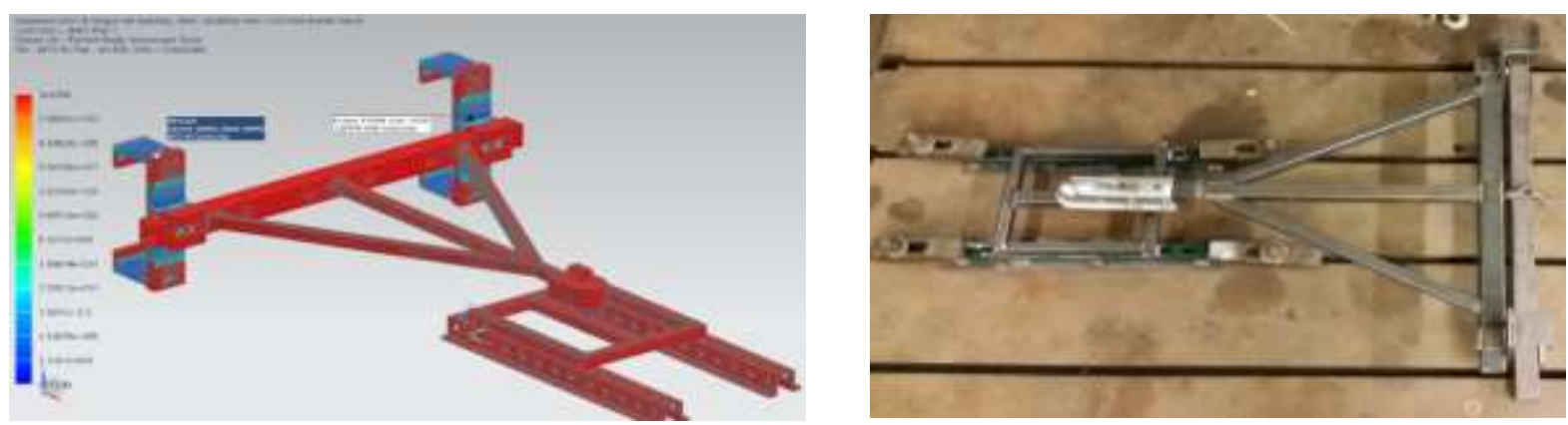

Figure 4: First version of manually adjustable gooseneck trailer hitch assembly $[6,7]$.

\subsubsection{Second trailer hitch design}

During Winter 2018 the capstone course was offered to only one student who needed to graduate at the end of that term. This student could not take the course due to schedule conflicts. Also, this student already secured a full-time engineering job and so, was a working (off-campus) student as far as Kettering is concerned. The same adjustable gooseneck trailer project was assigned to this student with an intent that the student needed to provide a totally different variation of the design than the manually adjustable one. Brief design details of the previous gooseneck project report were provided to the student.

The student used SolidWorks software [9] and proposed an entirely new design that uses a compliant polyurethane rubber bushing material to make the short link arm softer and vibration resistant. The position of the short link relative to the right hand side pin support can be adjusted to attain different axial loads on the short link when a fixed towing force is applied to the hitch ball on the left. Figure 5 shows the CAD drawing using SolidWorks, and the fabricated steel hitch assembly. This design is also expected to control the deflection in the direction of towing.
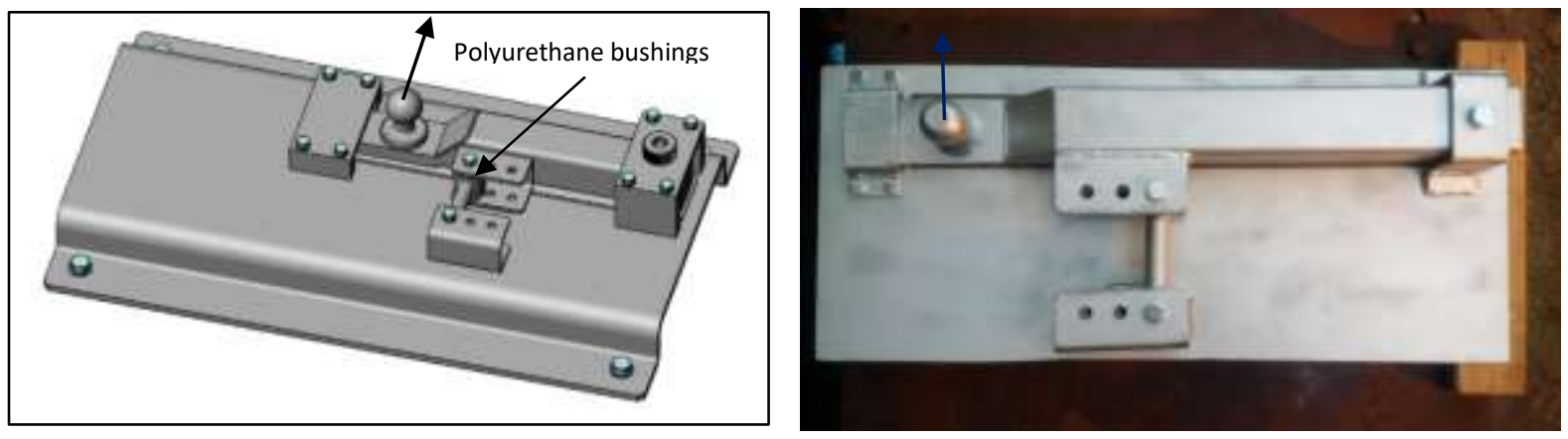

Figure 5: Adjustable gooseneck trailer hitch assembly using polyurethane bushings [6]. 
The characteristics of the bushing together with the short link arm have been tested experimentally using an appropriate 0.75 -ton ( $1500 \mathrm{lb}$ or pounds) capacity 'come-along', which is a hand operated winch loading device as shown in Fig. 6. An axle strap was wrapped around the gooseneck ball and attached to the chain come-along winch. The come-along was then attached at the other end to a steel work bench. The chain hoist was then tightened to its maximum capacity of $1500 \mathrm{lb}$. Although a load gage was not used to measure the actual force applied, it was noted that there was some slight compression as expected in the bushing assembly. There was no damage or deformation noted to any of the other steel components. It should also be noted that this test was performed with the link arm in the innermost position so the most deflection would have been observed here. If there was about $1500 \mathrm{lb}$ applied to the hitch ball, then the link arm would have had approximately $2510 \mathrm{lb}$ applied to it as it is located approximately two-third of the way down the long swing arm from the pivot point. The rating on the trailer ball itself is listed at $3500 \mathrm{lb}$. These are typically used for smaller single axle trailers such as those for boats, motorcycles, or construction materials. As can be observed, the experimental procedure provided qualitative measurements only.

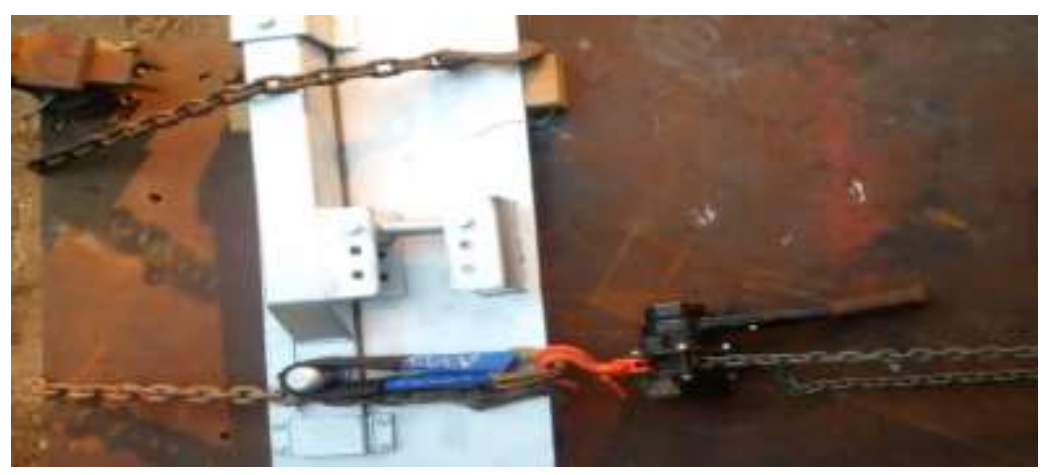

Figure 6: Experimental view of the adjustable hitch assembly [6].

Preliminary design calculations have been performed using Excel tool and by modelling the 3-inch $\mathrm{x}$ 3inch x 0.25-inch thick hollow long swing arm as a simply-supported steel beam with overhang on the left end. The loaded beam model along with the critical dimensions, pin supports at locations $\mathrm{A}$ and $\mathrm{B}$, and load at $\mathrm{C}$ is shown in Fig. 7. Assuming that the maximum tow load at $\mathrm{C}$ (hitch ball) is around $1500 \mathrm{lb}$, the force at $\mathrm{B}$ on the 1-inch diameter short link arm containing the polyurethane bushing can be calculated as 2910 $\mathrm{lb}$ approximately. This force represents the tensile force on the link arm, as bearing (compressive) force on the bushings, and as a shear force on the two bolts of the link arm assembly.

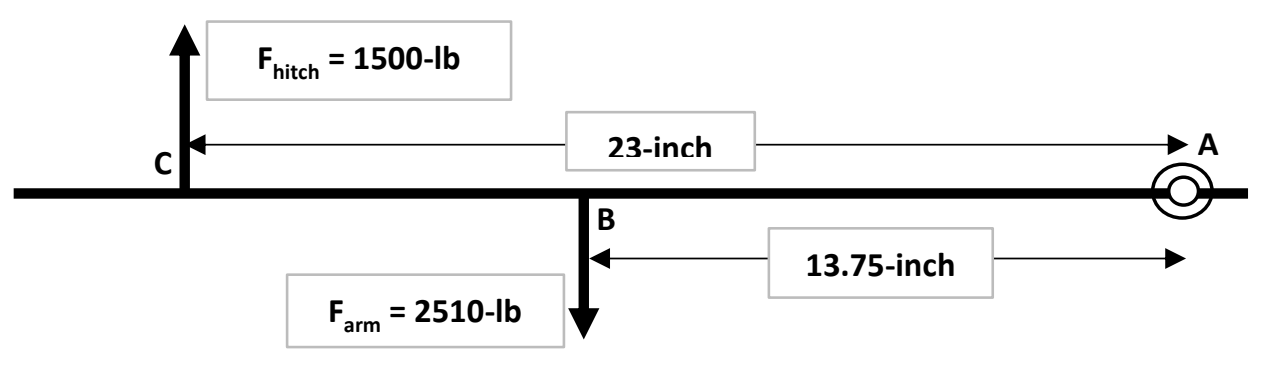

Figure 7: Beam model of the hitch assembly [6]. 
Following results have been obtained from the Excel calculations:

a) Deflection and bending stress of the long swing arm, $\mathrm{AC}=0.0056$-inch, and 5955 psi, respectively

b) Shear stress on each 9/16-inch grade 5 bolt attached at B to either side of the short link arm $=7743$ psi

c) Shear stress on the 5/8-inch grade 5 bolt attached at A to the long swing arm, AC $=2500$ psi

d) Tensile stress in the short link arm and bearing stress on bushings $=3196 \mathrm{psi}$, and $956 \mathrm{psi}$, respectively

All the stress values are well within yielding limits of the materials used for the assembly.

As stated earlier, the entire project work including the design and fabrication of the device has been carried out by the student using resources available at the company. However, due to time constraints, the student could not perform structural analysis using the CAE tool. The cost of this device is well below US $\$ 60$, compared to what is available in the market. The student also documented the safety issues and impact to society if the device is poorly designed for commercial use by an average person.

Student gave the feedback as: "This project allowed me to come up with a new idea and see it through the conceptual stage to a finished product. This also gave me the opportunity to test the device and compare the theoretical calculations to the actual results. This was confirmed when the load was applied to the finished assembly and nothing was damaged. This confirmed that the applied stresses did not surpass the yield stresses of the members and the fasteners."

\subsubsection{Preliminary analysis of the second trailer hitch assembly}

During Summer 2018 the author offered MECH-516 Applied FEA class to two on-campus and few other off-campus students. For the two on-campus students, as a part of their final project (for $10 \%$ weightage), FEA of the compliant trailer hitch system (second design) has been assigned. These students used NX CAE tool [10] and MatLab [11] to carry out the FEA studies. SolidWorks part files generated by the Winter 2018 capstone course student were given to the FEA course students. These students have to understand the details of the SolidWorks parts files before importing them to NX for any modifications of the same. The CAD model of the trailer hitch assembly shown in Fig. 8 is the image in NX. This figure shows the compliant short link arm, swing arm assembly, the hitch ball and the direction of pull force.

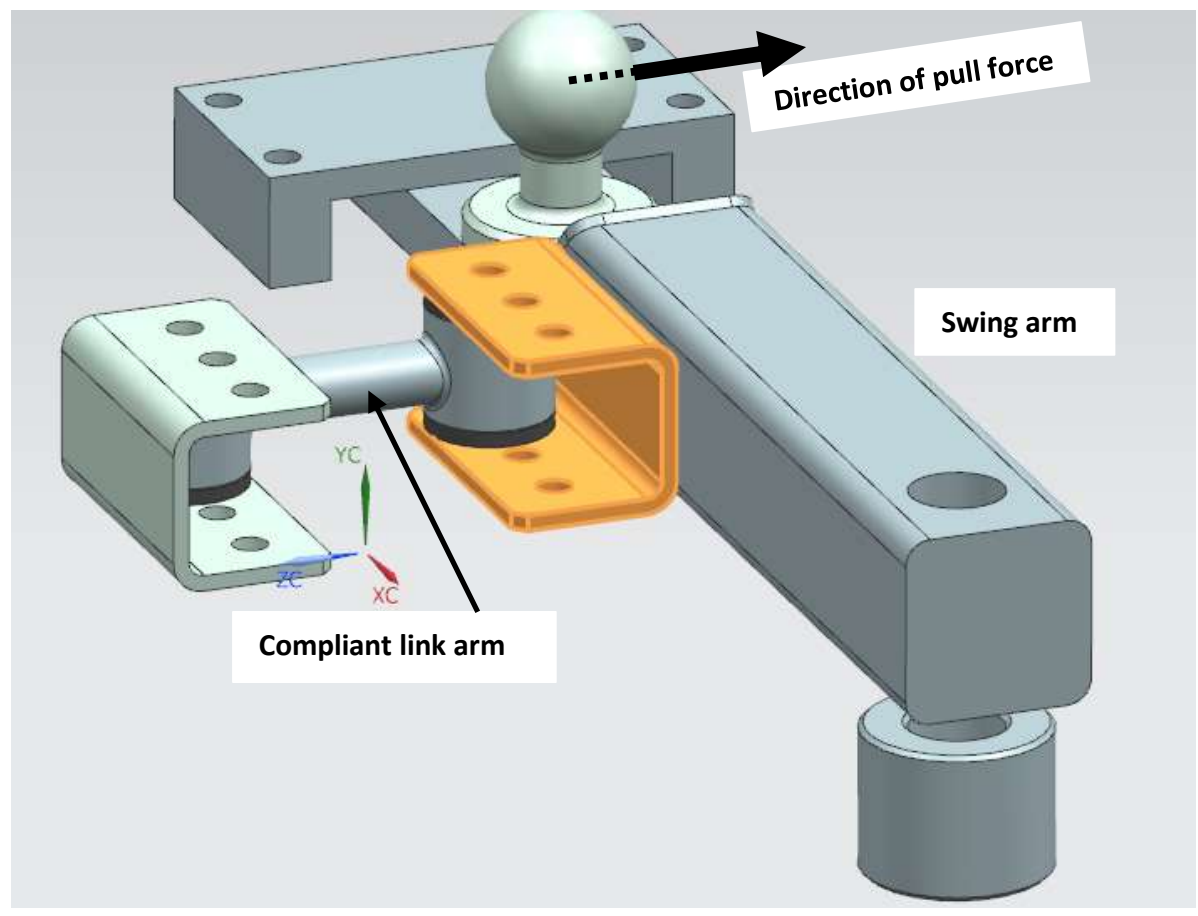


Figure 8: NX Screenshot depicting separate components within swing-arm hitch assembly.

This model was initially coarse-meshed using $2^{\text {nd }}$ order 10-noded tetrahedral elements. Different material properties needed to be inputted (one for polyurethane and rest all steel), and different contact surfaces needed to be defined between various joints to constrain (bond) the different components of the assembly. Several iterations have been performed to determine the optimum pull force that would yield acceptable limits of stress and deflection values. The maximum pull force is around 11,000 N. This represents the towing capacity of the trailer hitch. The maximum deflection of the swing arm from the CAE analysis came out to be around $20-\mathrm{mm}$.

The CAD model is simplified using three 1D beam elements (4 nodes) to perform finite element (FE) calculations using MatLab [11]. Solid mechanics calculations are also carried out to validate the order of magnitude of deflection results. The simplified FE model consisting of swing arm (elements 1 and 3), and an equivalent compliant lever arm (element 2) is shown in Fige 9. All the geometric dimensions (L1 to L4) have been measured from the actual fabricated device. The length of element 2 (dimension L1) is approximately 200-mm (or roughly 8-inch). FE analysis using MatLab yielded around 23-mm of deflection when the dimension is 'adjusted' to around 290-mm. Obviously, the 1D FE analysis results by MatLab, and the 3D CAE results did not match. However, the order of magnitude is around the same.

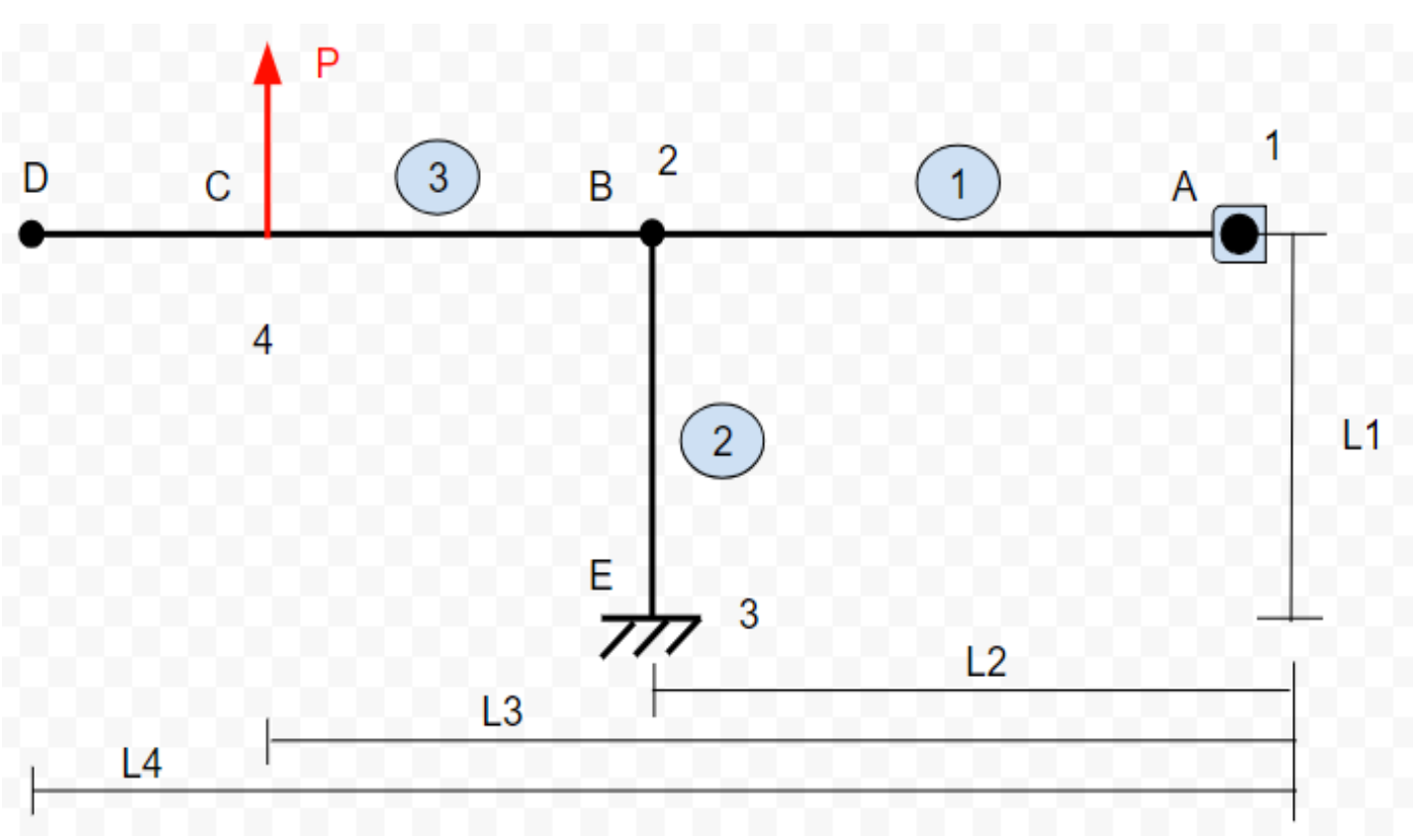

Figure 9: FE model of Swing/Lever Arm Assembly.

\subsection{Learning outcomes, societal impact and recommendations [6]}

The students documented several learning outcomes, impact to society due to poor ethics and designs, and finally proposed recommendations based on their experiences. They concluded that:

a) Allowing students to come up with different project ideas of their own is a good idea, and with the help of the instructor and the group members to narrow down their choices to one project to finally work on. 
b) This project required lots of knowledge in many areas of mechanical design, manufacturing, testing and project management. Initially, lots of time and effort was put into planning in order to choose the project idea and to complete the project within the available time constraints of 11 weeks.

c) This project provided the realization that physical reality is rather complex and becomes even more complex when one tries to predict how a physical system will react using techniques learned in theory classes.

d) Many assumptions were made for the theoretical analysis; however, they were vital in receiving any sort of result or prediction.

e) The CAE/FEA method is limited as to how well it can provide an accurate simulation - this is why many iterations of a problem must be performed in order to filter out bad data from good data.

f) The link arm for the second trailer hitch assembly provided valuable experience when using any sort of prediction method as it was a rather complex blend of geometries and materials; much effort was spent in order to determine the best way to model the link arm.

g) On the fabrication side, lots of welding and joining methodologies had to be used. Modelling joints and welds in CAE is always challenging.

h) Testing requires availability of sensors, measuring equipment and technician help that the labs do not currently possess.

i) A hitch assembly, such as the ones fabricated for this project, is a very commercial product. They must be able to withstand high loads (towing capacity) without failing.

j) Improper welding can alter the performance of materials within a system; therefore, recommended testing procedures need to be carried out to know if the integrity of the welds were good or not.

k) Failure of such a hitch system could result in the death or injury of citizens. It is our duty as engineers and ethical responsibility to understand and provide quality goods that the average person may use on a daily basis.

1) As modern simulation programs advance, they will likely become more popular to use among manufacturers; this requires the proper knowledge to be able to use and apply methods learned in all the classes.

m) As per recommendations to carry successful numerical analysis, actual experimental data for the gooseneck trailer hitch assembly must be provided in order to compare any predictive data.

n) Time and effort must be spent to understand how the materials perform under different loading conditions.

o) For the adjustable arm hitch assembly, an equivalent modulus of elasticity needed to be either found online or calculated: this could be obtained experimentally when the link arm was fabricated. Sensors and gages are needed to measure the applied force. This allows capturing the loading data. Finally, if more time was available, a proper simplified 3D model of the hitch assembly would need to be created in order to have a simulation using software such as NX or Solidworks tool.

Overall, it was an enjoyable experience for both students and the instructor.

\section{Summary and conclusions}

In this paper, a single capstone project carried by three different groups of students in different academic terms is presented. Both CAE and math tools have been used for design and analysis. Two different designs are presented and briefly discussed. The first one is designed theoretically analysed to be manually adjustable but it could not be fabricated that way. The second gooseneck hitch assembly involved a new idea and design to make it more compliant in the towing direction by using polyurethane bushings inside a link arm. But it lacked thorough analysis using CAE tools, and also lacked systematic testing procedure. The different designs presented here involved generating ideas, brainstorming to pick plausible ideas to develop preliminary designs, iterative analysis, procurement of bill of materials for the finally chosen device, fabrication \& assembly, and testing. Use of knowledge from the courses already taken is expected, 
while also realizing the gaps in knowledge for self-learning or with help from the instructor(s). Limitations of the designs and identification of the reasons for any failure along the way, or any hurdles faced was well documented. Also, ways to overcome the difficulties faced was reported. Finally, scalability issues, meaning how the ideas used in the developed device can be adapted easily to design another device with similar or different requirements. Mathematical equations are not presented in this paper since they are based on simple physics, solid mechanics and machine design courses. For similar reasons, tabular data is also not included here (for example, material properties and bill of materials), as it is not very important to understand the contents of the paper.

\section{Acknowledgements}

The author wishes to acknowledge the work carried by several capstone class students.

\section{References}

[1] Tomorrow's Professor Postings, 2007. Doing less work, collecting better data: Using Capstone Courses to Assess Learning. https://tomprof.stanford.edu/posting/821.

[2] R. C. Moore 2005. The capstone course. Assessing media education: A resource for educators and administrators. ed. W. G. Christ, Erlbaum Press, Hillsdale, NJ.

[3] Davis, D., Beyerlein, S., Davis, I. 2006. Deriving Design Course Learning Outcomes from a Professional Profile. International Journal of Engineering Education, vol. 22, no. 1.

[4] M. Plumley, W. Palm, and W. Simpson. 2008. A Common Design-Build-Test Project Incorporating Freshman and Senior Undergraduate Analysis Skills. Paper No. 185, Proceedings of ASEE Conference, Pittsburgh, PA.

[5] B. D. Lutz, et al. 2015. Student Perspectives on Capstone Design Learning. Paper No. 11556, Proceedings of ASEE Conferences, Seattle, WA.

[6] Several student capstone project reports. 2017 - 2019. Kettering University, Flint, MI.

[7] R. Echempati. 2018. Experiences and outcomes of teaching senior capstone course. Proceedings of Materials Science and Technology (MS\&T18) Conference, Columbus, Ohio.

[8] R. Echempati. 2019. Senior Mechanical Systems Design Capstone Projects: Experiences and Assessment. Proceedings of ASEE Conference, Tampa, FL.

[9] SolidWorks for Innovation by Dassault Systems. 2018. https://www.solidworks.com/

[10] NX for Design and Analysis. 2018. https://www.plm.automation.siemens.com/global/en/products/nx/ [11] MatLab: math, graphics and programming. 2018. https://www.mathworks.com/products/matlab.html 